\title{
mRNA Differential Display of Tea Leavse under Polyethylene Glycol Stress
}

\author{
Guinian Qi (Corresponding author), Jianbing Xia, Shengxiang Chen \& Yingjuan Chen \\ Department of Tea Science, College of Horticulture, Sichuan Agricultural University \\ No.46 Xin Kang Road, Ya'an 625014, Sichuan, China
}

$\&$

Key Laboratory of Tea Science and Engineering of Sichuan Province, Ya'an 625014, Sichuan, China

E-mail: guinian5612@sina.com.cn

This study was supported by Science \& Technology Department Project of Sichuan Province (2006-YZGG-8).

\begin{abstract}
Tea (Camellia sinensis L.) is one of the world's three largest beverages which play an important role in agricultural production of China, India, Sri Lanka and other countries. Gene expression of two years old Fuding-dabaicha was analyzed using DDRT-PCR under PEG6000 stress. Through the analysis and screening of experimental conditions and primers combination, a number of different fragments were obtained. By submitting to GeneBank and BLAST comparison, we identified three different fragments while only one has pigment-related gene fragment.
\end{abstract}

Keywords: Two years old Fuding tea tree, DDRT-PCR, PEG6000 stress

\section{Introduction}

Drought is one of the main environmental factors which limit the world's crop production. Global arid and semi-arid regions account for about $36 \%$ of the total land area and $43 \%$ of arable land. In china, about half of the land is arid and semi-arid regions. Drought occupies the first in all abiotic stress to crop yields loss, second only to the loss of biological stress caused by pets (Shanfu Chen \& Qingyao Shu,1999,p555-560).

Studies of plants drought resistance started earlier and ranged from the morphological analysis (Hervé Cochard \& S.Tete Barigah, Marc Kleinhentz, 2008, p976-982), physiological index (P.Songsri, S.Jogloy \& T. Kesmala, 2008, p2245-2253; Carlos German Muñoz-Perea, Henry Terán, Richard G. Allen, \& James L. Wright, 2008, p2111-2120), to the research that focus on the molecular level studies now (Hong hong Hu, Mingqiu Dai \& Jialing Yao. 2006, p12987-12992; Yuemin Huang, Benze Xiao \& Lizhong Xiong, 2007, p73-85; Benze Xiao, Xichen \& Chengbin Xiang, 2009, p73-83). With a detailed study on the mechanism of drought gradually down to the molecular level, a lot of drought related genes were found but most of them focus on Arabidopsis, rice, corn and so on.

Tea prefers moisture and largely depends on water. However, some tea-growing areas of precipitation are not enough and this leads to restrictions on tea production. In addition, as global warming, water shortage will become more serious.

The current researches about tea drought resistance mainly in physiological filed and molecular aspects studies are little. In this paper, using mRNA different display technique, gene expression under PEG6000 stress environment was studied in tea.

\section{Materials and Methods}

\subsection{Plant material, stress induction and RNA isolation}

Two years old tea (Camellia sinensis $c v$. Fuding-dabaicha) was selected. It was washed and then cultured in $1 / 2$ Hoagland nutrient solution 3 days based on the same size. After that, it was put in 20\% polyethylene glycol (PEG6000) solution to make a drought environment. Stress treatment time was as follows: 1d (P1), 2d (P2), 3d (P3). The control was cultured in the same volume of distilled water (CK) and repeated three times.

Total RNA was isolated by RNA isolation kit following manufacture's protocol (RNAout Column Plant RNAout, TIANDZ, Beijing).Then $4 \mu \mathrm{L}$ total RNA extraction liquid was taken to separated $1.5 \%(\mathrm{w} / \mathrm{v}) 10 \times \mathrm{TAE}$ by $2 \%$ agarose gel electrophoresis at $80 \mathrm{mv}$ for $30 \mathrm{~min}$. 


\subsection{Differential display}

Three anchored primers (Table 1) were used and cDNA first strand synthesis was performed as following manufacture's protocol (Revert Aid ${ }^{\mathrm{TM}}$ First Strand cDNA Synthesis Kit \#K1621, Fermentas, Canada). Eighteen random primers (Table1) were used for differential display PCR and it was performed in $25 \mu \mathrm{L}$ reaction mixture, using four dilutions of the first strand cDNA. Each reaction mixture contained $1 \mu \mathrm{L}$ of each anchored primer and random primers, $2 \mu \mathrm{L}$ cDNA, $12.5 \mu \mathrm{L}$ Master-mix, $14 \mu \mathrm{L} \mathrm{ddH}_{2} \mathrm{O}$. The reaction was performed using a PCR Instrument (Bio-Rad, USA) programmed to $95^{\circ} \mathrm{C}$ for $5 \mathrm{~min}$ to initial denaturation followed by 35 cycles of $45 \mathrm{~s}$ of denaturation at $95^{\circ} \mathrm{C}, 45 \mathrm{~s}$ annealing at $45^{\circ} \mathrm{C}$, extension at $72^{\circ} \mathrm{C}$ with a final extension period of $10 \mathrm{~min}$ at $72^{\circ} \mathrm{C}$. The PCR products $(4 \mu \mathrm{L})$ were separated $1.5 \%(\mathrm{w} / \mathrm{v}) 10 \times \mathrm{TBE}$ by agarose gel electrophoresis at $120 \mathrm{mv}$ for 1h. (Primers in table 1 all referenced Ashok K. Jain, 2001,p59-67, and Lina Sha, Fengling FU \& Wanzhen $\mathrm{Li}, 2006, \mathrm{p} 365-370)$

\subsection{Sequencing and comparison}

Selected interested segments, recycling by kit (E.Z.N.A. ${ }^{\mathrm{TM}}$ Gel Extraction Kit (50) D2500-1, OMEGA, USA).Connected segments to pMD19-T Simple Vector:T-vector $1 \mu \mathrm{L}$,segment $4 \mu \mathrm{L}$,solution I $5 \mu \mathrm{L}$,link $16^{\circ} \mathrm{C}$ overnight.Transformed into competent cells of E.coli $\mathrm{DH} 5 \alpha(100 \mu \mathrm{L}$ E.coli, $10 \mu \mathrm{L}$ plasmid), after culture chosen positive clones and further with the M13 primers colony PCR identification: $12.5 \mu \mathrm{L}$ Mix, $2.5 \mu \mathrm{L}$ primer M13( \pm ), $10 \mu \mathrm{L}$ ddH2O, total $25 \mu \mathrm{L}$. Finally, chosen positive clones to puncture cultured $16-24 \mathrm{~h}$ in $37^{\circ} \mathrm{C}$ and send to Invitrogen biotechnology Co., Ltd sequencing. The results were submitted to the Gene Bank for BLAST alignment.

\section{Results}

\subsection{Changes of plant shape}

Compared to control, there was clear droughty trait on the treatment plant. Like Fig 1.

\subsection{RNA isolation}

Agarose gel electrophoresis results showed that $18 \mathrm{~s}$ and $28 \mathrm{~s}$ of total RNA were clear and it meant that total RNA extracted could be used in reverse transcription reaction. Like Fig 2.

\subsection{PCR products}

Electrophoresis results showed that the PCR product of control was the most abundant, with the longer of processing time, the less abundant of treatments. The different combination of AP and RP had significant differences in bands. Due to space limitation, only a picture was displayed. Fig 3.

A band about 550bp (in white box in figure) was chosen and sent to sequencing. Then BLAST in GeneBank.

\subsection{Alignment analysis}

By submitting to NCBI and comparing fragments, we found that it had $75 \%$ homology with Camellia sinensis clone Sajin tea leaf mutant color tag S31.B15 genomic sequence (Accession: DQ443473.1)and 72\% with Vitis vinifera contig VV78X260735.4, whole genome shotgun sequence (Accession: AM461193.2). Compared with DNAMAN software, some results were shown as follows:
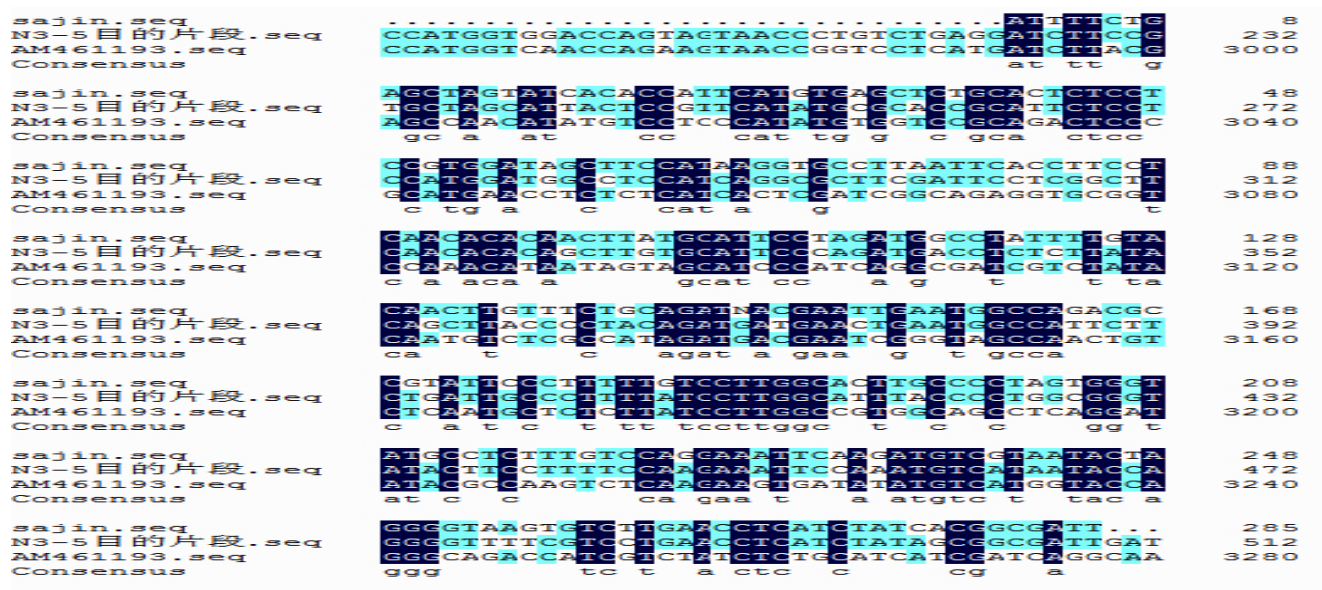


\section{Discussion}

DD-PCR was discovered by two scientists at Harvard Medical School P.Liang and A.D Pardee since 1992, it had aroused wide interest for benefits because this technology is simple and quick and can analysis simultaneously two or more samples. It has been successfully applied in a variety of plant resistance research, for example, studies about identification of drought-responsive transcripts in peanut (Ashok K. Jain, Sheikh Mehboob Basha, C. \& Corley Holbrook.2001, p59-67) which got several mRNA transcripts that were up-regulated or down-regulated following water stress. Researches about differential gene expression profiles analysis of tea plant induced Tea Looper (Ectropic oblique) attack using DDRT-PCR (Chaoling Wei, Xiangfeng gao \& Aihua Ye, 2007, p133-140) found many differential expression fragments and some of them were firstly found in molecular mechanism studies of plant-insect interaction. But this technique has a high false-positive defect, while improving the annealing temperature is a major improvement measure. In this experiment, exploring three annealing temperature of $42^{\circ} \mathrm{C}, 45^{\circ} \mathrm{C}$ and $50^{\circ} \mathrm{C}$, we found $45^{\circ} \mathrm{C}$ was the best temperature for the better reproducibility results(date not shown). However, some bands maybe disappear due to higher anneling temperature which leads to difficulty in primer pair. Therefore, further studies are needed.

In this paper, gene expression has significant differences under drought condition: many down-regulated fragments even disappeared while some of them almost remained unchanged and a part of them up-regulated. By sequencing, we got a nucleic acid band may be close to pigment. Generally, pigment plays an important role in the maintenance of leaf color, flower or other parts of plant, but deeper study found that some pigments had other physiological functions such as secondary metabolite. Anthocyanin is a widely researched pigment and it was found to have many physiological effects. Anthocyanin is a water-solubility plant pigment, existing in 27 genus and 72 species of angiosperms, determining flowers, fruits and seeds' color (ANNAMARYJU D S,1997, p671-674). There are higher content in plants grape, hawthorn, pine needle, ginggko, peanuts, tea and so on. It belongs to flavonoid of phenolic compounds and has function of anti-oxidant, anti-mutation, strengthening the immune system, etc. A variety of regulatory genes adjust anthocyanin synthesis, in which plant MYB protein was the main factor, whiche one of the four main stress resistance related transcription factors (Yunrong Zhao, Shilei Wang, 2008, p3095-3097, Zhiru Xu, Chunlei Li, 2008, p597-604). Studis found that numbers of cloning new genes MYB transcription factors are drought-tolerance, high temperature, low temperature effects. For example, AtMYB2 (Hoeren FU, Dolferus R \& Wu Y, et al, 1998, p479-490) and AtMYB60 (Cominelli E, Galbiati M \& Vavasseur A, 2005, p1196-2000) in Arabidopsis were proved to participate in the process of plant drought stress. Over expression osmyb4 gene in Oryza (Vannini C, Locatelli F \& Bracale M, 2004, p115-127) could significantly increase GM crops to drought, high salt and UV radiation tolerance. Some studies believe that with the severity of water stress, anthocyanin content was growing and phenylalanine lyase (PAL) activity was on the rise (Liying Xu, Yuping Hao \& Gang Wang, 2007, 168-172). Kashmir Singh believes that anthocyanin reductase (CsANR) expression is down-regulated in the tea under drought stress (Kashmir Singh, Arti Rani \& Asosii Paul, 2009, 837-846) and successfully cloned this gene. So we can speculate that the fragment in this experiment not only associate with tea leaf color change but also have relationship with drought resistance.

\section{Aknowlegement}

When completing this paper, Dr.Li Cheng-lei gave much help and I was very grateful.

\section{References}

Chen shan-fu, Shu qing-yao. (1999). Biological Mechanism of and Genetic Engineering for Drought Stress Tolerance in Plants. Chinese Bulletin of Botany, 16(5):555-560.

Hervé Cochard, S.Tete Barigah, \& Marc Kleinhentz, et al. (2008). Is xylem cavitation resistance a relevant criterion for screening drought resistance among Prunus species? Journal of Plant Physiology, 165:976-982.

P. Songsri, S. Jogloy, \& T. Kesmala, et al. (2008). Heritability of Drought Resistance Traits and Correlation of Drought Resistance and Agronomic Traits in Peanut. Crop Science, 48:2245-2253.

Carlos German Muñoz-Perea, Henry Terán, \& Richard G. Allen, et al. (2006). Selection for Drought Resistance in Dry Bean Landraces and Cultivars. Crop Science, 46: 2111-2120.

Hong hong $\mathrm{Hu}$, Mingqiu Dai, \& Jialing Yao, et al. (2006). Overexpressing a NAM, ATAF, and CUC (NAC)transcription factor enhances drought resistance and salt tolerance in rice. PANS, 103(35):1297-1292.

Yuemin Huang, Benze Xiao, Lizhong Xiong. (2007). Characterization of a stress responsive proteinase inhibitor gene with positive effect in improving drought resistance in rice. Planta, 226:73-85.

Ben-Ze Xiao, Xi Chen, \& Cheng-Bin Xiang, et al. (2009). Evaluation of Seven Function Known Candidate Genes for their Effects on Improving Drought Resistance of Transgenic Rice under Field Conditions. Molecular 
Plant, 2(1):73-83.

Ashok K. Jain, Sheikh Mehboob Basha, \& C. Corley Holbrook. (2001). Identification of drought-responsive transcripts in peanut (Arachis hypogaea L.). Electronic Journal of Biotechnology, 4(2):59-67.

SHA Li-na, FU Feng-ling, \& LI Wan-chen. (2006). mRNA DIFFERENT EXPRESSION OF DROUGHT TOLERANT INBRED LINE UNDER DROUGHT CONDITIONS IN MAIZE. Journal of Nuclear Agricultural Sciences, 20(5):365-370.

Wei Chao-ling, GaoXiang-feng, \& Ye Ai-hua, et al. (2007). Dif-ferential Gene Expression Profiles Analysis of Tea Plant Induced by Tea Looper (Ectropic oblique) Attack Using DDRT-PCR. Journal of Tea Science, 27(2):133-140.

ANNAMARYJU D S. (1997). Antioxidant ability of anthocyanins against ascorbic acid oxidation. Phytochemistroy, 45(4):671-674.

ZHAO Yunlong, Wang Shilei. (2008). Research Progress of Anthocyanin. Journal of Anhui Agriculture Science, 36(8): 3095-3097.

XU Zhi-RU, LI Chun-Lei, \& CUI Guo-Xin, et al. (2008). MYB Protein of Anthocy-Anin Biosynthesis in Plant. Plant Physiology Commynications, 44(3):597-604.

Hoeren FU, Dolferus R, \& Wu Y, et al. (1998). Evidence for a role for AtMYB2 in the induction of the Arabidopsis alcohol dehydrogenase gene (ADH1) by low oxygen. Genetics, 149(2):479-490.

Cominelli E, Galbiati M, \& Vavasseur A, et al. (2005). Aguard-cell-specific MYB trans-cription factor regulates stomatal movements and plant drought tolerance. Curr Biol, 15(13):1196-2000.

Vannini C, Locatelli F, \& Bracale M, et al. (2004). Overexpression of the rice Osmyb4 gene increases chilling andfreezing tolerance of Arabidopsis thaliana plants. Plant Journal, 37(1):115-127.

XU Li-ying, HE Yu-ping, \& WANG Gang, et al. (2007). Effect of Water Stress on Pingment Content and PAL Activity of Purple Leaf Plum. Journal of Jilin Agricultural University, 29(2):168-172.

Kashmir Singh, Arti Rani, \& Asosii Paul, et al. (2009). Differential display mediated cloning of anthocyanidin reductase gene from tea (camellia sinensis) and its relationship with the concerntration of epicatechics. Oxford Journals tree physiology, 26(6):837-846.

Table 1. The Primers 'composition and nature

\begin{tabular}{|c|c|c|}
\hline Primer type & Primer code & Base composition \\
\hline \multirow[b]{2}{*}{ Anchored Primer,AP } & $\mathrm{AP}_{1}$ & $5^{\prime}$-Oligo d $(\mathrm{T})_{11} \mathrm{~A}-3^{\prime}$ \\
\hline & $\begin{array}{l}\mathrm{AP}_{2} \\
\mathrm{AP}_{3}\end{array}$ & $\begin{array}{l}\text { 5'-Oligo d(T })_{11} \mathrm{G}-3^{\prime} \\
5^{\prime} \text {-Oligo d }(\mathrm{T})_{11} \mathrm{C}-3^{\prime}\end{array}$ \\
\hline \multirow{18}{*}{ Random Primer,RP } & $\mathrm{RP}_{1}$ & 5'-TACAACGAGG-3' \\
\hline & $\mathrm{RP}_{2}$ & 5'- TTTTGGCTCC-3' \\
\hline & $\mathrm{RP}_{3}$ & 5'- TCGGTCATAG-3' \\
\hline & $\mathrm{RP}_{4}$ & 5'- GATCTGACAC-3' \\
\hline & $\mathrm{RP}_{5}$ & 5'- GATCAATCGC-3' \\
\hline & $\mathrm{RP}_{6}$ & 5'-GGTACATTGG-3' \\
\hline & $\mathrm{RP}_{7}$ & 5'-GGAACCAATC-3' \\
\hline & $\mathrm{RP}_{8}$ & 5'-CTGCTTGATG-3' \\
\hline & $\mathrm{RP}_{9}$ & 5'-СТTTCTACCA-3' \\
\hline & $\mathrm{RP}_{10}$ & 5'-GATCGCATTG-3' \\
\hline & $\mathrm{RP}_{11}$ & 5'-GATCTGACTG-3' \\
\hline & $\mathrm{RP}_{12}$ & 5'-TGCTGGGGA-3' \\
\hline & $\mathrm{RP}_{13}$ & 5'-TGCTGGTGG-3' \\
\hline & $\mathrm{RP}_{14}$ & 5'-TGCTGGTAG-3' \\
\hline & $\mathrm{RP}_{15}$ & 5'-TGCTGGGTG-3' \\
\hline & $\mathrm{RP}_{16}$ & 5'-TGCTGTATG-3' \\
\hline & $\mathrm{RP}_{17}$ & 5'-TGGAGCTGG-3' \\
\hline & $\mathrm{RP}_{18}$ & 5'-TGTGGCAGG-3' \\
\hline
\end{tabular}



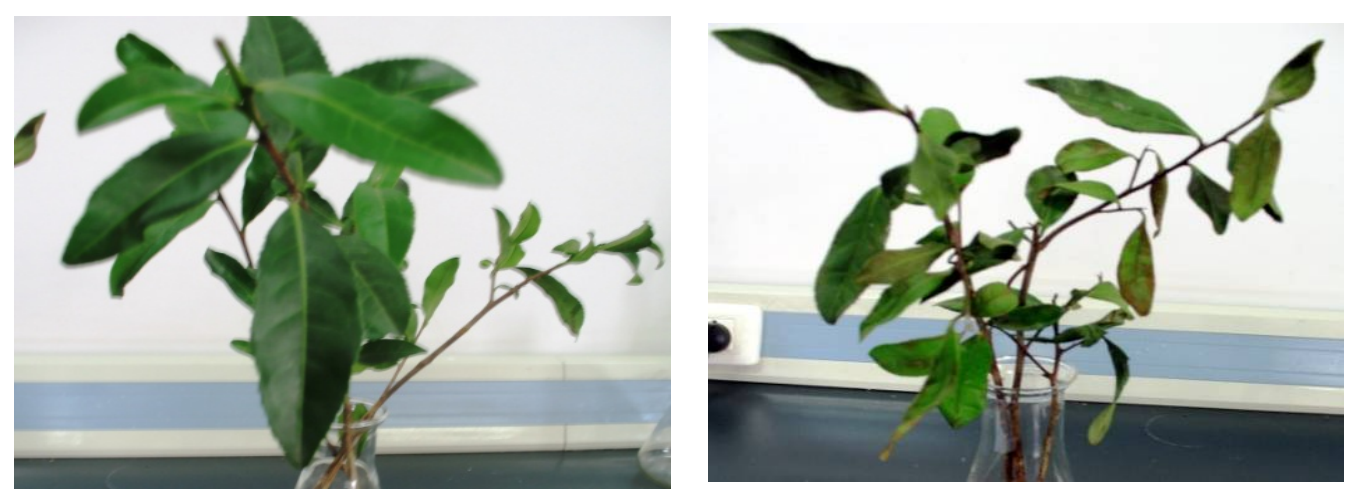

Figure 1. The traits' difference between control and treatment in 3 days

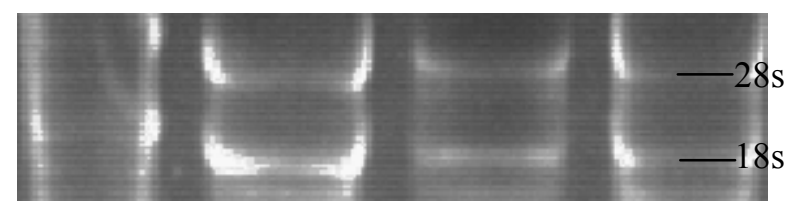

Figure 2. Agaros electrophoresis of the total RNA(From right to left:ck,treatment 1,2,3 days)

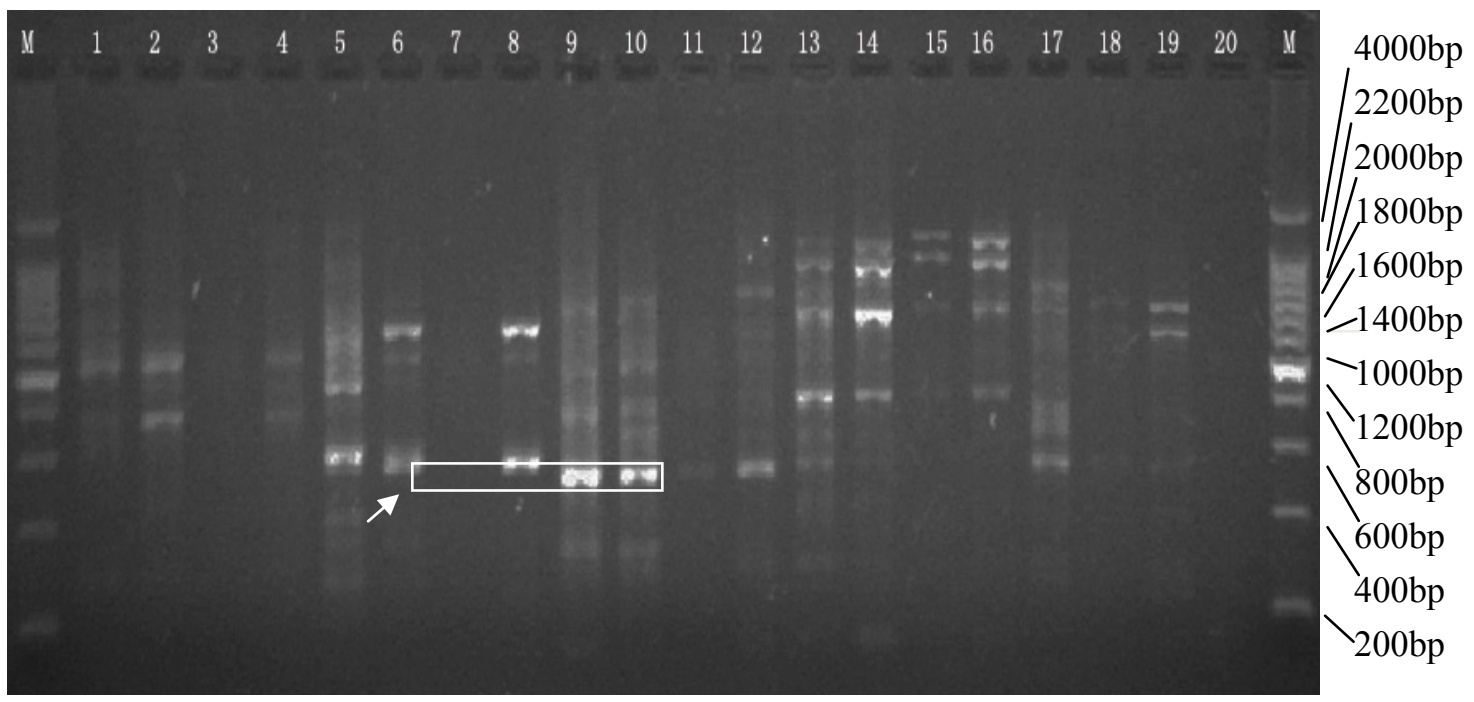

Figure 3. The PCR product of the same primer and different drought days 